\title{
Secretory Breast Carcinoma, a Case Report and Literature Review
}

\author{
Hayet Laajili1 ${ }^{*}$, Amina Ben Salem², Sonia Zaidi ${ }^{3}$, Imen Bannour¹, Khouloud Marzouk1, \\ Asma Korbi ${ }^{1}$, Raja Faleh ${ }^{1}$ \\ ${ }^{1}$ Department of Obstetrics and Gynecology, Medical University of Monastir, Monastir, Tunisia \\ ${ }^{2}$ Department of Radiology, Medical University of Monastir, Monastir, Tunisia \\ ${ }^{3}$ Department of Oncology, Medical University of Monastir, Monastir, Tunisia \\ Email: ^hlaajili@gmail.com
}

How to cite this paper: Laajili, H., Salem, A.B., Zaidi, S., Bannour, I., Marzouk, K., Korbi, A. and Faleh, R. (2017) Secretory Breast Carcinoma, a Case Report and Literature Review. Open Access Library Journal, 4: e3591.

https://doi.org/10.4236/oalib.1103591

Received: April 10, 2017

Accepted: May 15, 2017

Published: May 18, 2017

Copyright (c) 2017 by authors and Open Access Library Inc.

This work is licensed under the Creative Commons Attribution International License (CC BY 4.0).

http://creativecommons.org/licenses/by/4.0/

\begin{abstract}
Secretory breast carcinoma ( $\mathrm{SBC}$ ) is a very rare subtype of breast carcinoma that reported mostly in young women, with a median age of 25 years. Despite the low frequency, SBC elicits pathologic interest because of their unique morphology and excellent prognosis. Authors report a 23-year-old woman presented with a nodule in retro areolar region of her right breast. Microbiopsic examination revealed neoplastic tissue. Pathological examination of tumor revealed SBC. This tumor is morphologically characterized by the presence of abundant eosinophilic secretions in intracellular vacuoles and intercellular spaces. The objective of this paper is to review the epidemiological, clinical, paraclinical and therapeutic aspects of SBC from a case report and literature review.
\end{abstract}

\section{Subject Areas \\ Oncology, Women's Health}

\section{Keywords}

Breast, Breast Diseases, Breast Neoplasms, Secretory Breast Carcinoma

\section{Introduction}

Secretory breast carcinoma (SBC) is a very rare subtype of breast carcinoma and comprises less than $0.15 \%$ of invasive breast cancers. SBC was first described by McDivitt and Stewart in 1966 in young children and named "the disease juvenile carcinoma". SBC is morphologically characterized by the presence of abundant eosinophilic secretions in intracellular vacuoles and intercellular spaces. The descriptive term "secretory carcinoma" therefore, replaced the original designation 
of "juvenile carcinoma" [1] [2]. Despite the low frequency, SBC elicits pathologic interest because of their unique morphology and excellent prognosis. The aim of this article is to report medical history and treatment of a SBC in a young woman and literature review.

\section{Case Report}

A 23-year-old woman was admitted to the Department of Obstetrics and Gynaecology complaining of a lump in her right breast. She has no familial history of breast cancer. She has a familial history of endometrial cancer. The lump was discovered three months ago. The physical examination revealed a $3 \times 3 \mathrm{~cm}$ tumor located in the retro areolar region of her right breast. The mass was mobile and not painful. No skin dimple, nonipple retraction or nipple discharge were observed. No clinical axillary lymph node involvement was detected.

Mammography and ultrasonography showed a $3 \mathrm{~cm}$ hypoechoicmacrolobulated nodule classified as BI-RADS 4 [Figure 1]. Microbiopsic examination revealed neoplastic tissue. There was no evidence of metastatic disease on evaluation. The patient underwent a conservative treatment of the breast (lumpectomy with axillary dissection). Pathological examination of tumor revealed SBC characterized by abundant eosinophilic secretions in intracellular vacuoles and intercellular spaces [Figure 2]. The tumor was $2 \times 2 \mathrm{~cm}$ grade 1 as classified by

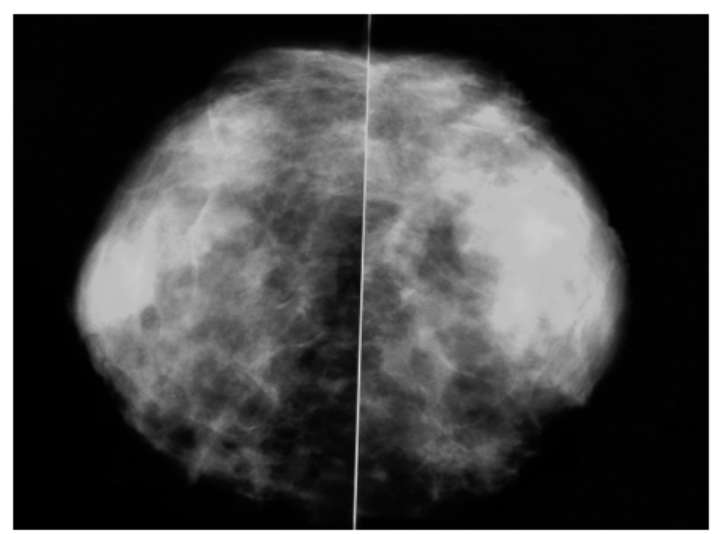

Figure 1. Right retro areolar nodule classified as BIRADS 4 at mammography.

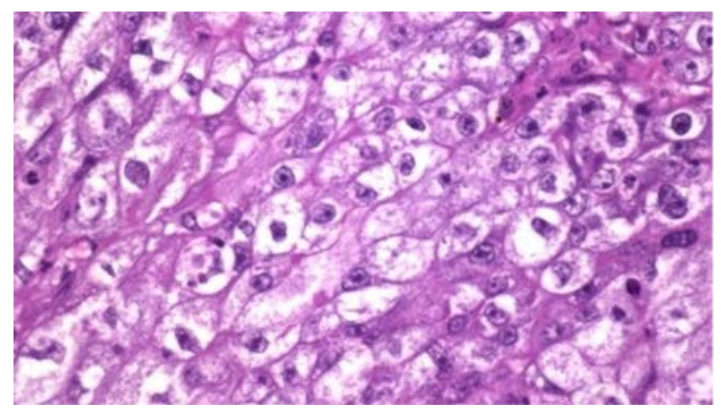

Figure 2. Abundant eosinophilic secretions in intracellular vacuoles and intercellular spaces $(\mathrm{HE} \times 200)$. 
Scarff Bloom Richardson. The surgical margins were free. Lymph node metastases were detected in one of the 23 dissected lymph nodes. Immunohistochemical staining showed triple negative breast cancer (triple negative for estrogenreceptors, progesterone receptors and Her2/neu).Thereafter the patient was treated by adjuvant chemotherapy (Fluorouracil, Adriamycine, Cyclophosphamide and taxanes) and radiotherapy. She is healthy after more than 24 months of followup.

\section{Discussion}

SBC is a very rare subtype of breast carcinoma. It is reportedas short clinical case series. SBC occurs in both children and adults with a wide age range from 3 to 83 years. Most reported cases are in young women, with a median age of 25 years. Some cases have been also reported in men, mostly in young men with a median age of 19 years. Male to female ratio is $1 / 6$ [3] [4]. The typical clinical presentation is a mobile and palpable mass. The tumor may be non-palpable and be detected by a nipple discharge or by a radiologic lesion. The most common location of SBC appears to be the upper-outer quadrant, but it can occur in any part of the breast [2] [5] [6]. A rare occurrence in the ectopic breast tissue of the axilla has been also reported.

Descriptions of mammographic findings are sparse in the literature. Many case reviews reported that the mammographic findings of SBC are variable and non-specific, ranging from no abnormal findings or benign-looking nodular density to suspicious malignant lesions with spiculated margins or microcalcifications. Sonography frequently showed small well-marginated or partially microlobulatedisoechoic or hypoechoic nodules, indistinguishable from some benign masses as well as other well-circumscribed malignancies [1] [2] [5] [6].

Secretory breast carcinoma has 2 characteristic histologic features, an abundant periodic Acid Schiff Positive intracellular and extracellular secretions and a granular eosinophilic cell cytoplasm [1] [5] [6]. On immunohistochemistry the tumor cells are positive for S-100 protein but usually negative for estrogenreceptors, progesterone receptors, and HER2/neu (triple negative breast carcinoma). Recent reports suggest that SBC express basal-cell markers including cytokeratins 5, 6, 14 and $17 \mathrm{c}$-Kit (CD117), epidermal growth factor receptor and Vimentin. Recently, the tumor was found to be associated with a distinct ETV6NTRK3 mutation which confers the tumor proliferative and survival advantage [7] [8] [9].

Because SBC is a rare type of breast carcinoma, there are no consensus guidelines for treatment. Recommendations vary among authors. Large surgical excision is the main treatment for SBC. In children local excision with sentinel lymph node mapping is the preferred initial treatment. If sentinel lymph node contain metastatic carcinoma, additional lymph nodes are removed. However, a conservative treatment of the breast is not always possible because of the location of the tumor. Mastectomy is occasionally required and may cause psychosocial difficulties in adolescent females lives [3] [4] [10]. SBC is considered to be 
more aggressive in adult women than in children. For patients over 20 years old a simple mastectomy with sentinel lymph node biopsy is preferred for neoplasms larger than $2 \mathrm{~cm}$. If the result of sentinel lymph node biopsy is negative, patient can be exempted from axillary lymph node dissection [3] [5] [10].

The real value of postoperative chemotherapy or radiotherapy is not yetestablished. Adjuvant radiotherapy may be indicated after conservative surgery in adult patients but is not recommended for the treatment of primary tumors in children because of the risk of significant complications, including pulmonary fibrosis and damage to bone growth. Radiotherapy is usually recommended after local recurrence. Adjuvant chemotherapy is especially indicated in patients with node-positive disease. The hormonal treatment has no place in SBC.

Distant metastases are rare and have been reported in few cases. The local recurrence rate is $33 \%$ with breast conservation surgery. Local recurrence may occur after 20 years. Therefore long-term follow-up is necessary. The favorable prognostic factors include tumors less than $2 \mathrm{~cm}$ in size, age less than 20 years at the time of diagnosis and tumors with circumscribed margins [1] [5] [10].

\section{Conclusion}

SBC is a rare subtype of breast cancer. It is characterized by distinct histological, immunohistochemical and ultrastructural features as well as specific molecular genetics. They usually present as deceptively well-circumscribed mobile and slow-growing masses which may mimic benign lesions clinically and radiologically. SBC occurs in both sexes with a wide age range. Hormone receptors and HER2/neu tests are frequently negative. As a rare type of breast carcinoma, there are at present, no consensus guidelines for treatment. Conservative surgery owing to high rate of local recurrence has the little role in adults. The real value of postoperative radiotherapy and chemotherapy has not been established and further studies are required to establish treatment algorithms and guidelines.

\section{Patient Consent Obtained}

The authors report no actual or potential conflict of interest in relation to this article.

\section{References}

[1] Sung, H.M., Ko, E.Y., Han, B.-K., Jung, H.S., Kim, S.J. and Cho, E.Y. (2008) Secretory Carcinoma of the Breast Sonographic Features. Journal of Ultrasound in Medicine, 27, 6947-6954.

[2] Vieni, S., Cabibi, D., Cipolla, C., Fricano, S., Graceffa, G. and Latteri, M.A. (2006) Secretory Breast Carcinoma with Metastatic Sentinel Lymph Node. World Journal of Surgical Oncology, 4, 88. https://doi.org/10.1186/1477-7819-4-88

[3] Bhagwandeen, B.S. and Fenton, L. (1999) Secretory Carcinoma of the Breast in a Nine-Year-Old Boy. Pathology, 31, 166-168. https://doi.org/10.1080/003130299105386

[4] Roth, J.A., Discafani, C. and O’Malley, M. (1988) Secretory Breast Carcinoma in a Man. American Journal of Surgical Pathology, 12, 150-154. 
https://doi.org/10.1097/00000478-198802000-00009

[5] Yilmaz, K.M., Pak, I., Atalay, C., et al. (2009) Histopathological and Clinical Characteristics of Secretory Carcinoma of the Breast. Turkish Journal of Medical Sciences, 39, 155-159.

[6] Anderson, P., Albarracin, C.T. and Resetkova, E. (2006) A Large Fungating Breast Mass: Secretory Carcinoma with Apocrine Differentiation. Archives of Pathology \& Laboratory Medicine, 130, e50-e52.

[7] Lae, M., Freneaux, P., Sastre-Garau, X., Chouchane, O., Sigal-Zafrani, B. and Vincent-Salomon, A. (2009) Secretory Breast Carcinomas with ETV6-NTRK3 Fusion Gene Belong to the Basal-Like Carcinoma Spectrum. Modern Pathology, 22, 291298. https://doi.org/10.1038/modpathol.2008.184

[8] Lambros, M.B., Tan, D.S., Jones, R.L., et al. (2009) Genomic Profile of a Secretory Breast Cancer with an ETV6-NTRK3 Duplication. Journal of Clinical Pathology, 62, 604-612. https://doi.org/10.1136/jcp.2008.059675

[9] Diallo, R., Schaefer, K.L., Bankfalvi, A., Decker, T., Ruhnke, M., Wulfing, P., Jackisch, C., Luttges, J., Sorensen, P.H., Singh, M. and Poremba, C. (2003) Secretory Carcinoma of the Breast: A Distinct Variant of Invasive Ductal Carcinoma Assessed by Comparative Genomic Hybridization and Immunohistochemistry. Human Pathology, 34, 1299-1305. https://doi.org/10.1016/s0046-8177(03)00423-4

[10] Tixier, H., Picard, A., Guiu, S., et al. (2011) Long-Term Recurrence of Secretory Breast Carcinoma with Metastatic Sentinel Lymph Nodes. Archives of Gynecology and Obstetrics, 283, 77-78. https://doi.org/10.1007/s00404-010-1669-9

Submit or recommend next manuscript to OALib Journal and we will provide best service for you:

- Publication frequency: Monthly

- 9 subject areas of science, technology and medicine

- Fair and rigorous peer-review system

- Fast publication process

- Article promotion in various social networking sites (LinkedIn, Facebook, Twitter, etc.)

- Maximum dissemination of your research work

Submit Your Paper Online: Click Here to Submit

Or Contact service@oalib.com 